\title{
Эволюция института совета директоров в российских компаниях: от формальной роли к реальной
}

\author{
Дуляк Ю.И. ${ }^{5}$
}

В статье рассматривается авторский подход $\kappa$ периодизаџии этапов эволюиии совета директоров в российских компаниях. Оценены перспективы и возможности дальнейшего развития этого института. Автор выделяет этапь на основе того, как менялась роль советов в российских компаниях. В результате исследования выделено три этапа эволючии роли совета директоров в России. Кроме этого, продемонстрирована система факторов (институциональная среда, правовое поле, человеческий фактор, экономическое окружение, факторы корпоративного сектора), оказывающуая влияние на деятельность совета.

JEL: D23, G30, G32, G34, P26, P31

\begin{abstract}
Ключевые слова: корпоративное управление, эволючия совета директоров, эффективность деятельности, Россия
\end{abstract}

Специфика формирования тех или иных институтов зависит от особенностей среды, в которой они возникают. Появление и развитие корпоративного управления в России - не исключение. Данный институт был внедрен сверху в начале 1990-х, он возник вследствие изменений, имевших место в российской экономике и политике: происходило разрушение старых экономических связей и переход к новым, рыночным, отношениям. Трансформация общественно-экономических отношений требовала появления новых институтов, формирования соответствующей инфраструктуры, структурных изменений.

В работе будет проанализирована история развития института совета директоров в российских компаниях. Мы выделим этапы эволюции совета директоров в России и оценим перспективы и возможности дальнейшего развития этого института. При этом этапы будут определены на основе того, как менялась роль советов в российских компаниях. Классически совет директоров рассматривается как посредник между собственниками и менеджерами, который способствует сглаживанию конфликтов между ними. Особенности модели корпоративного управления, которая складывалась в России, обусловили специфику совета директоров: в условиях российской действительности совет не выполнял тех функций, которые на него возложены. Его роль трансформировалась в зависимости от изменения макроэкономических и микроэкономических условий. Среди факторов, стимулирующих эволюцию роли совета, есть факторы как внешней, так и внутренней среды организации: институциональная среда, правовое поле, человеческий фактор, экономическое окружение. Делая периодизацию на основе критерия эволюции роли совета директоров, мы будем понимать, что данная трансформация происходит под воздействием изменения обозначенных выше факторов. В заключение будет сделана итоговая таблица, содержащая информацию о наличии или отсутствии того или иного фактора на каждом этапе эволюции роли совета в российских компаниях. Отметим также, что функции, выполняемые советом директоров, различаются для разных типов компаний, в особенности публичных и непубличных. Более того, изменение роли совета в этих компаниях идет в разные сроки, что

\footnotetext{
5 Аспирантка кафедры микроэкономического анализа НИУ ВШЭ, стажер-исследователь ИАПР НИУ ВШЭ, преподаватель кафедры Экономики и финансов фирмы НИУ ВШЭ.

Статья подготовлена в рамках работы над темой Программы фундаментальных исследований НИУ ВШЭ 2012 года «Институциональная эволюция промышленных предприятий в переходной экономике». Автор благодарит д-ра эконом. наук. Т.Г. Долгопятову за комментарии и замечания.
} 
делает периодизацию несколько условной. Информационную основу анализа составляют исследования специалистов в области корпоративного управления и корпоративное законодательство.

\section{1. Исторический контекст. Первый этап (начало 1990-х - 1998 год) - формальный характер совета директоров}

Становление и развитие института корпоративного управления, в частности совета директоров, стало следствием перехода к экономической системе, основанной на принципах конкуренции. Причем все реформы и изменения носили радикальный характер и «...определялись в основном представлениями властных структур о рыночной экономике» (Кузнецов, 2003). Корпоративные отношения в начале 1990-х годов рассматривались субъектами рыночной экономики как способ перераспределения влияния и контроля (Редькин, 2003). Все экономические агенты находились в равных условиях и преследовали схожие цели, поэтому, рассуждая о роли совета директоров в российских компаниях этого периода (начало 1990-х - 1998 год), мы будем говорить обо всех АО в целом.

Как отмечает А. Радыгин, исходным пунктом для анализа вопросов корпоративного управления в российских компаниях является изучение структуры акционерного капитала, которая, в свою очередь, была определена в результате реализации приватизации (Радыгин, 1995). В итоге приватизации появились предприятия с высокой концентрацией собственности. Исследования демонстрируют, что к 2000-м годам доля крупнейшего акционера в капитале промышленного предприятия составляла 40-50\% (Интеграционные процессы... 2006). Более того, опросы подтверждали, что у двух третей ОАО существовал контролирующий предприятие собственник.

В сложившихся условиях высокой концентрации капитала на первый план выходили частные группы интересов, т.е. интересы блокхолдеров. Потенциальная угроза утраты контроля заставляла директоров использовать оборотные средства компаний для скупки акций у других собственников с целью сохранения своего контроля (Яковлев, Данилов, 2007). Для сглаживания потенциальных конфликтов между мажоритарными и миноритарными акционерами было необходимо внедрение правовых институтов, развитие корпоративного права. Для регламентации деятельность приватизированных предприятий с 1 января 1996 года был введен в действие Федеральный закон «Об акционерных обществах» № 208-Ф3. До утверждения данного закона деятельность компаний регулировалась лишь подзаконными актами и указами Президента РФ, которые не могли справиться с многочисленными злоупотреблениями и нарушениями: в обороте находились акции, которые не прошли государственную регистрацию, акции выпускались лицами, не имеющими на это права, и т.д. Такое значительное количество нарушений практически не вызывает удивления: ваучерная приватизация закончилась раньше, чем было сформировано корпоративное законодательство. Для прекращения царившего хаоса помимо Ф3 «Об акционерных обществах» были введены и другие федеральные законы, регулирующие корпоративные отношения, но они содержали множество пробелов, требовали дополнений содержательного и редакционного характера. Более того, многие акционерные общества не следовали предписаниям этих нормативно-правовых актов: или по причине незнания, или по причине непонимания сути закона.

А. Яковлев основную причину этого видит в том, что инициатором всех законодательных инициатив выступает государство, в то время как спрос на право реально проявляется в поведении экономических агентов, т.е. в их отношении к конкретным законам (Яковлев, 2003). По мнению автора, стратегия игнорирования закона об АО возникла в 1990е годы А. Яковлев отмечает, что логика формирования российского корпоративного законодательства базировалась на импорте институтов без учета интересов экономических агентов и особенностей формирования прав собственности (Яковлев, 2003). В результате принудительного акционирования создавались квазиоткрытые АО, которые не нуждались во 
внешних инвесторах, а поэтому, по большому счету, требовали иной правовой формы.

Какое же место в системе корпоративного управления занимал совет директоров в конце 1980-х, начале 1990-х и в 1998 году? Совет директоров носил формальный характер, так как его функции были не отделены от функций других органов управления компанией. Это объясняется рядом причин. Права и обязанности совета директоров были установлены законодательно, но использовать по назначению этот институт еще не научились. Любые институты, в том числе совет директоров, являются продуктом эволюции и отражают практику реальных отношений (Кузнецов, 2003). Формальный характер совета директоров объяснялся неготовностью управленцев сходу воспринимать нововведения, внедрять и по назначению использовать институт совета директоров (Радыгин, 1995). Должности топменеджеров приватизированных компаний заняли бывшие «красные директора» с определенным менталитетом и сложившимся стилем управления. Более того, в России была сформирована инсайдерская модель корпоративного управления с концентрированной собственностью. Советы использовались в интересах собственников. Согласно законодательству, они имели возможность по собственному усмотрению формировать совет директоров, а при желании даже возглавлять его. В исследовании середины 1990-х годов отмечается, что в 97\% приватизированных предприятий бывший директор, т.е. новоиспеченный собственник, занял должность председателя совета директоров (президента, председателя правления, генерального директора) или сразу несколько указанных должностей (Радыгин и др., 2003).

\section{2. Интеграция, глобализация и новая роль совета директоров (1999- 2007)}

Если институт совета директоров в начале и середине 1990-х годов носил условный характер, поскольку и оперативный, и стратегический контроль над предприятием был у крупнейшего акционера, то после кризиса 1998 года совет директоров стал постепенно использоваться как инструмент повышения инвестиционной привлекательности компании, хотя все еще находился под полным контролем собственника. Отметим, что на этом этапе мы рассуждаем в основном о холдинговых компаниях.

Микроэкономические и макроэкономические аспекты оказали воздействие на природу корпоративных отношений в конце 1990-х - начале 2000 годов, в том числе на изменение роли совета директоров. После финансового кризиса 1998 года стало очевидно, что в России появились крупные бизнес-группы, которые сформировались в результате действий государства, а именно политики залоговых аукционов, специфической приватизации с выстраиванием вертикально интегрированных компаний в нефтяном бизнесе и т.д. (Долгопятова, 2004). С. Авдашева отмечает, что корпоративные отношения (наравне с другими процессами) в холдингах развиты в большей степени, чем в независимых фирмах, что в рамках холдингов бизнес-процессы, характерные для современного российского корпоративного сектора (повышение концентрации собственности, становление элементов корпоративного управления), пошли несколько дальше, нежели в типичной автономной компании (Авдашева, 2007).

В чем проявлялась необходимость совершенствования корпоративных отношений крупными компаниями? Наличие возможности увеличить долю фирмы на рынке и привлечь дополнительное финансирование особенно актуально в период экономического роста и выхода российских компаний на международный рынок. Развитие внутреннего рынка, а также растущие возможности самих компаний подталкивали их к выходу на международные площадки, к поиску новых источников финансирования. В 2001-2002 годах начался рост капитализации российского фондового рынка, которая к марту 2003 году составила 127 млрд долл. (Standard\&Poor's, 2003).

Таким образом, после того как большинство крупных бизнес-групп завершили консолидацию собственности, их владельцы оказались заинтересованы в привлечении внешнего финансирования, тем более что многие крупные и средние компании достигли 
потолка эффективности использования собственных ресурсов, а выход на глобальные рынки позволял привлечь заемные средства (Потанин, 2003). Приоритеты собственников сменились: если на первом этапе они были заинтересованы в приобретении, удержании и реструктуризации активов, то теперь они хотели повысить качество управления с целью привлечения средств инвесторов. Собственники российских компаний почувствовали потребность в развитии корпоративных отношений, так как именно соответствие международным стандартам корпоративного управления позволяло добиться доверия со стороны иностранных партнеров и повысить репутацию фирмы. Мотивом к улучшению качества корпоративного управления служила не только потребность в привлечении заемных средств, но и необходимость оценки бизнеса рынком. Тем не менее внутрикорпоративные практики работы совета директоров, как и прежде, в большей степени носили формальный характер, хотя совет директоров уже служил инструментом повышения инвестиционной привлекательности. Вот как об этом пишет С. Авдашева: «В этом контексте корпоративные действия выступают скорее элементом имитации для достижения демонстрационного эффекта либо для привлечения внешних инвесторов, роль которых в качестве источника финансирования незначительна и опять имеет в большей степени демонстрационный, а не финансовый характер» (Авдашева, 2007).

Если на первом этапе эволюции совета директоров советы создавались потому, что так было предписано законом об АО, то в начале 2000-х годов состав и деятельность советов определялись требованиями бирж и рекомендациями различных деловых и общественных объединений. Например, чтобы разместить свои акции на ведущей фондовой бирже России, компаниям следовало соответствовать ее требованиям по формированию состава и структуры совета директоров. Зарубежные фондовые площадки выдвигали для российских эмитентов еще более жесткие требования. Например, исследование 2006 года продемонстрировало, что в России более 100 компаний (57\% - публичные компании, 43\% непубличные) имеют в составе совета независимых директоров (Ассоциация независимых директоров, 2006). Интересно отметить, что среди факторов, повлиявших на привлечение независимых директоров в советы, авторы выделяют не внутренние потребности компании, а ожидание портфельных и стратегических инвесторов, а также подготовку к выходу на IPO.

Поскольку новая рыночная конъюнктура требовала несколько иных стандартов корпоративного управления, возникала необходимость совершенствования корпоративного права. Так, в 2002 году был разработан Кодекс корпоративного поведения, значительная часть которого посвящена рекомендациям по формированию совета директоров. Улучшению стандартов корпоративного управления способствовало также возникновение в это же время различных неправительственных организаций: Ассоциации по защите прав инвесторов, Наблюдательного совета по корпоративному управлению, Ассоциации независимых директоров, Российского института директоров, Национального совета по корпоративному управлению (Standard\&Poor's, 2003).

В большинстве случаев соответствие международным стандартам корпоративного управления было формальным выполнением требований фондовых рынков, реальные внутренние преобразования происходили нечасто. Например, разделение собственности и менеджмента происходило все в тех же холдингах и публичных компаниях, деятельность которых была слишком масштабна для управления одним лишь собственником (Dolgopyatova, Iwasaki, Yakovlev, 2009). Интервью с руководителями 20 ОАО, проведенные в начале 2000-х годов, подтверждают, что более чем в половине компаний присутствовал собственник как минимум с 50\%-ным пакетом акций. На шести объектах также наблюдался значимый уровень концентрации: было выявлено наличие акционера, владеющего от $25 \%$ до $50 \%$ акций (Долгопятова, 2004). Однако были и примеры реальной экспертной работы советов.

У непубличных компаний стимулов к изменению положения совета директоров в компании не было, поэтому роль совета директоров в них мало изменилась. В подтверждение этого приведем результаты опроса (исследование 2001-2002 годов) членов 
совета директоров и правлений 31 АО Свердловской, Челябинской, Курганской областей. Были опрошены 72 человека (члены совета директоров и высших менеджеров): на вопрос, соблюдается ли, по мнению респондентов, баланс интересов между менеджментом и акционерами, только $11 \%$ ответили утвердительно, $54 \%$ считают, что такой баланс присутствует только в некоторой степени, $28 \%$ - в минимальной степени, $7 \%$ - отсутствует. Подобные ответы свидетельствую о том, что советы директоров не выполняют функцию урегулирования корпоративных конфликтов (Романова, Ткаченко, 2004).

\section{3. Развитие института совета директоров как инструмента для внутреннего управления компанией (2008 год - по настоящее время)}

Как правило, переломные, кризисные, моменты обостряют имеющиеся проблемы фирмы. Так произошло с кризисом 1997-1998 годов, который помог осознать, что банки не могут самостоятельно давать адекватную оценку стоимости фирмы и что оценка компании рынком более эффективна, в результате чего произошло некое смещение от континентальной модели корпоративного управления к англосаксонской (Яковлев и др., 2010). Однако кризис 2007-2009 годов продемонстрировал, что оценка стоимости бизнеса рынком тоже недостаточно объективна. Данный кризис в первую очередь был связан с падением фондового рынка, поэтому в большей степени отразился на публичных компаниях, о которых мы продолжаем рассуждать, хотя компании непубличные также ощутили на себе влияние кризиса.

Так, кризис 2008 года выявил множество пробелов в практике применения корпоративного управления российскими компаниями. Т. Долгопятова выделила ряд последствий кризиса для сферы корпоративного управления: усиление оппортунизма менеджмента; начало нового витка перераспределения акционерной собственности, ведущего к нарушениям прав мелких акционеров; приостановление отхода крупных акционеров от участия в исполнительном управлении и др. (Долгопятова, 2009). Группой исследователей был также сделан интересный вывод касательно кризиса 2007-2009 годов: проблемы корпоративного управления стали следствием не только возросшего оппортунизма менеджеров, но и существенного ослабления позиций собственников в результате размывания пакетов акционеров в гонке за финансовыми ресурсами (Яковлев и др., 2010). Этот процесс был характерен для публичных корпораций, которые размещали свои акции на фондовых рынках и из мажоритарных акционеров превращались в миноритариев. В результате интересы акционеров и их горизонты планирования изменились, как следствие усилилась агентская проблема.

Результаты исследование практики российского корпоративного управления по итогам 2004-2009 годов, проведенного Российским институтом директоров (РИД), подтверждают изменение роли корпоративного управления. Авторы делают вывод, что с наступлением кризиса корпоративное управление, как атрибут внешней инвестиционной привлекательности фирмы, не дает прежнего эффекта (Исследование практики корпоративного управления... 2010). Демонстрационного эффекта становится недостаточно. Корпоративное управление необходимо совершенствовать в целях повышения эффективности бизнеса, следуя логике его развития. Это значит, что корпоративное управление должно быть направлено на удовлетворение внутренней потребности компании. Исследование РИД подтверждает, что более распространенной стала практика создания механизмов, снижающих риск возникновения конфликта интересов у членов совета: доля компаний, создавших подобные механизмы, выросла за анализируемый период на 29 процентных пункта, до 73\%, среди публичных компаний - на 23 процентных пункта, до 79\%. Кроме того, в компаниях чаще стали создаваться комитеты по аудиту и по кадрам и вознаграждениям: доля таких фирм возросла до 77 и 65\% соответственно. Отметим, что растет число независимых директоров в составе совета. Помимо этого, собственники начинают осознавать значимость индивидуальных характеристик членов совета, которые 
обеспечивают эффективность работы совета в целом. В компаниях создаются программы для повышения квалификации членов совета, а также к их работе привлекаются внешние консультанты: доля публичных компаний, в которых существует практика регулярного повышения квалификации членов совета, возросла с 11\% в 2005 году до 18\% в 2008 году. Однако подчеркнем, что исследование РИД затрагивает всего 150 крупнейших публичных российских компаний.

Мировой финансовый кризис выявил недостатки правовых и регуляторных механизмов. В связи с этим после 2008 года значительно возросла законотворческая активность, касающаяся различных аспектов корпоративного управления. Приняты законы «О консолидированной финансовой отчетности», «О противодействии неправомерному использованию инсайдерской информации и манипулированию рынком», поправки в законы «Об акционерных обществах» и «О рынке ценных бумаг», которые предусматривают совершенствование процедур выплаты дивидендов и повышения прозрачности структуры собственности (Standard\&Poor's, 2011). Важным фактором в развитии института совета директоров стало также усиление административной ответственности на финансовых рынках благодаря вступлению в силу с 13 апреля 2009 года Федерального Закона № 9-Ф3 «О внесении изменений в Кодекс Российской Федерации об административных правонарушениях в части усиления административной ответственности за нарушение законодательства Российской Федерации об акционерных обществах, об обществах с ограниченной ответственностью, о рынке ценных бумаг и об инвестиционных фондах и Федеральный закон «О рынке ценных бумаг» в части уточнения определения и конкретизации признаков манипулирования ценами на рынке ценных бумаг». Несмотря на положительные изменения в законодательстве и совершенствование практики корпоративного управления, до сих пор сохраняются пробелы в корпоративном праве, а корпоративные отношения требуют дальнейших улучшений.

\section{4. Вместо заключения: основные выводы и перспективы исследований}

В исследовании было выделено три этапа эволюции роли совета директоров в российских компаниях. Каждый этап характеризуют определенные изменения, происходящие на микро- и макроуровнях. В ходе работы мы показали, что институциональная среда, поведение экономических агентов, правовое поле оказывают воздействие на деятельность совета директоров российских компаний. Данные факторы (как вновь возникшие, так и преобразованные имеющиеся) влияют на изменение роли совета, а поэтому являются критерием завершения одного этапа и начала другого. Подобная система основных характеристик внешней и внутренней среды фирмы, определяющих эволюцию роли совета в российских компаниях, представлена в таблице 1.

Таблица 1

Факторы, влияющие на трансформацию роли совета директоров в российских компаниях, на различных этапах его развития ${ }^{6}$

\begin{tabular}{|c|c|c|c|}
\hline & $\begin{array}{l}\text { Формальный } \\
\text { характер СД }\end{array}$ & $\begin{array}{c}\text { СД как инструмент } \\
\text { повышения } \\
\text { инвестиционной } \\
\text { привлекательности }\end{array}$ & $\begin{array}{c}\text { СД как } \\
\text { инструмент для } \\
\text { внутреннего } \\
\text { управления } \\
\text { компанией } \\
\end{array}$ \\
\hline \multicolumn{4}{|l|}{ Правовые факторьл } \\
\hline $\begin{array}{lr}\text { Наличие } & \text { законодательных } \\
\text { инициатив } & \text { в } \quad \text { сфере } \\
\text { корпоративного управления }\end{array}$ & $+/-$ & + & + \\
\hline
\end{tabular}

\footnotetext{
${ }^{6}$ Знаки «+» или «-» означают наличие или отсутствие того или иного фактора на определенном этапе эволюции роли совета директоров.
} 


\begin{tabular}{|c|c|c|c|}
\hline $\begin{array}{l}\text { Соответствие } \\
\text { законодательных инициатив } \\
\text { интересам } \quad \text { экономических } \\
\text { агентов }\end{array}$ & - & $+/-$ & $+/-$ \\
\hline $\begin{array}{l}\text { Защищенность } \\
\text { собственности }\end{array}$ & - & $+/-$ & $+/-$ \\
\hline \multicolumn{4}{|l|}{ Человеческий фактор } \\
\hline $\begin{array}{l}\text { Осознание необходимости } \\
\text { новой модели управления и } \\
\text { готовность } \\
\text { нововведения }\end{array}$ & - & $+/-$ & $+/-$ \\
\hline $\begin{array}{lcr}\text { Наличие } & \text { знаний } & \text { и } \\
\text { компетенций } & \text { в } & \text { сфере } \\
\text { управления } & & \\
\end{array}$ & - & $+/-$ & + \\
\hline \multicolumn{4}{|c|}{ Факторы институциональной средыл } \\
\hline $\begin{array}{l}\text { Нестабильность } \\
\text { институционального } \\
\text { окружения }\end{array}$ & + & $+/-$ & $+/-$ \\
\hline $\begin{array}{l}\text { Наличие } \\
\text { неправительственных } \\
\text { общественных организаций }\end{array}$ & - & + & + \\
\hline \multicolumn{4}{|l|}{ Экономические факторы } \\
\hline $\begin{array}{l}\text { Распределение } \\
\text { собственности } \\
\text { (приобретение и удержание } \\
\text { активов) }\end{array}$ & + & - & - \\
\hline 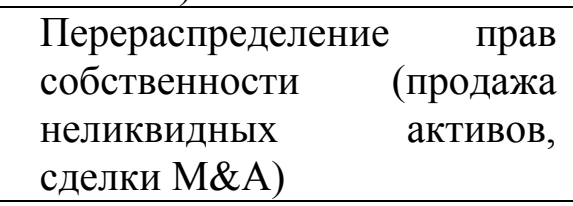 & - & + & + \\
\hline $\begin{array}{l}\text { Усиление } \\
\text { давления, } \\
\text { глобализацией }\end{array}$ & $+/-$ & + & + \\
\hline $\begin{array}{lr}\text { Привлечение } & \text { внешнего } \\
\text { финансирования } & \text { через } \\
\text { механизмы } & \text { фондового } \\
\text { рынка } & \\
\end{array}$ & - & + & $+/-$ \\
\hline \multicolumn{4}{|c|}{ Факторы корпоративного сектора } \\
\hline $\begin{array}{lll}\text { Сращивание } \\
\text { управления }\end{array}$ & + & $+/-$ & $+/-$ \\
\hline $\begin{array}{l}\text { Высокая концентрация } \\
\text { собственности }\end{array}$ & + & $+/-$ & $+/-$ \\
\hline $\begin{array}{l}\text { Привлечение для } \\
\text { управления профессионалов } \\
\text { в качестве менеджеров }\end{array}$ & - & + & + \\
\hline $\begin{array}{lr}\text { Следование международным } \\
\text { стандартам } & \text { корпоративного } \\
\text { управления } & \text { (создание } \\
\text { системы } & \text { внутреннего } \\
\text { контроля, } & \text { наличие } \\
\text { независимых } & \text { директоров, } \\
\text { создание комитетов при Сд) } \\
\end{array}$ & - & $+/-$ & $+/-$ \\
\hline
\end{tabular}




\begin{tabular}{|l|r|r|r|}
\hline $\begin{array}{l}\text { Механизмы мотивации } \\
\text { менеджеров, }\end{array}$ & & \\
обеспечивающие привязку & - & - & $+/-$ \\
их личных интересов к & - & & \\
долгосрочным интересам & & & \\
компании & & & \\
\hline
\end{tabular}

На первом этапе (начало 1990-х - 1998 год) совет директоров существовал лишь формально, не выполняя функции урегулирования корпоративных конфликтов, вся управленческая власть была сосредоточена в руках доминирующего собственника. На втором этапе (1999-2007) для собственников публичных компаний совет директоров становится рычагом, позволяющим завоевать доверие со стороны иностранных партнеров и привлечь средства инвесторов. Роль совета директоров заключалась в повышении инвестиционной привлекательности фирмы. В компаниях непубличных изменение роли совета директоров шло медленнее или не происходило вовсе. По сути, совет директоров в этих компаниях, как и прежде, оставался формальным институтом. На третьем этапе (2008 год - по настоящее время) совет директоров становится инструментом для удовлетворения внутренней потребности компании. Собственники стали осознавать, что корпоративное управления необходимо для повышения качества управления, которое способствует более эффективной работе компании. Данные изменения начались, но идут довольно медленными темпами. Новая (реальная) роль совета директоров в российских компаниях - это предпосылка для появления исследований в области воздействия характеристик совета на результаты деятельности компаний.

\section{Список литературы}

1. Авдашева С.Б. Российские холдинги: новые эмпирические исследования // Вопросы экономики. 2007. № 1. С. 98-111.

2. Анализ инфраструктуры корпоративного управления в России: сохранится ли стремление к реформам корпоративного управления и принесет ли оно плоды // Standard\&Poor's. M., 2011.

3. Долгопятова Т.Г. Корпоративное управление в российских компаниях: роль глобализации и кризиса // Вопросы экономики. 2009. № 6. С. 83-96.

4. Долгопятова Т.Г. Собственность и корпоративный контроль в российских компаниях в условиях активизации интеграционных процессов // Российский журнал менеджмента. 2004. № 2. С. 3-26.

5. Долгопятова Т.Г. Корпоративное управление в России: акционерная собственность и акционерный контроль в компаниях // Российская экономика на новых путях / под ред. Э.И. Гойзмана, Р.Н. Евстигнеева. М., 2004. С. 12-24.

6. Интеграционные процессы, корпоративное управление и менеджмент в российских компаниях // Московский общественный научный фонд / отв. ред. Т.Г. Долгопятова. M., 2006.

7. Исследование практики корпоративного управления в России: сравнительный анализ по итогам 2004-2009 гг. Новые тенденции в 2009 году. М., 2010.

8. Кузнецов Б.В. Развитие спроса на институты на примере корпоративного законодательства (взгляд экономиста) // Развитие спроса на правовое регулирование корпоративного управления в частном секторе. М., 2003.

9. Коллективный портрет независимого директора // Исследование Ассоциации независимых директоров. М., 2006.

10. Корпоративное управление в условиях финансово-экономического кризиса. Исследование Национального совета по корпоративному управлению и компании КПМГ. М., 2009. 
11. Корпоративное управление в России. Аналитический отчет // Standard\&Poor's. M., 2003.

12. Независимые директора на дороге не валяются. Комментарий руководителя ФСФР. [Электронный pecypc].

URL: http://www.ffms.ru/ru/press/interviews/index.php?id_3=6165\&year_3=2010\&month_3=4.

13. Потанин В. Корпоративное управление: на пути к «российской модели» // Россия в глобальной политике. 2003. № 3.

14. Радыгин А.Д. Российская приватизация: национальная трагедия или институциональная база постсоветских реформ? // Мир России. 1998. № 43(VII). С. 332.

15. Радыгин А.Д., Энтов Р.М., Межераупс И.В. Особенности формирования национальной модели корпоративного управления. М., 2003.

16. Радыгин А.Д., Гутник В.П., Мальгинов Г.Н. Постприватизационная структура акционерного капитала и корпоративный контроль: «контрреволюция управляющих»? // Вопросы экономики. 1995. № 10. С. 47-69.

17. Редькин И. Основные этапы развития спроса на корпоративное право в России // Развитие спроса на правовое регулирование корпоративного управления в частном секторе. М., 2003.

18. Романова О.А., Ткаченко И.Н. Эмпирический анализ институциональной динамики внутрифирменных корпоративных отношений (опыт регионального исследования 1999-2002 гг. в Уральском регионе) // Интерпериодика. 2004. № 2. С. 104-115.

19. Романова О.А., Ткаченко И.Н. Некоторые аспекты теории и практики эффективного корпоративного управления // Вестник УГТУ-УПИ. 2003. № 9. С. 13-20.

20. Усиление административной ответственности на финансовых рынках: практические вопросы - интервью с замруководителя ФСФР Александром Синенко. [Электронный pecypc]. URL: http://www.finmarket.ru/z/nws/interview.asp?id=1293454.

21. Энтов Р., Радыгин А., Межераупс И., Щвецов П. Корпоративное управление и саморегулирование в системе институциональных изменений. М.: ИЭПП, 2006.

22. Яковлев А.А. Спрос на право в сфере корпоративного управления: эволюция стратегий экономических агентов // Развитие спроса на правовое регулирование корпоративного управления в частном секторе. М., 2003.

23. Яковлев А.А. Корпоративное управление и реструктуризация предприятий в России: формальные институты и неформальные интересы собственников // Экономический журнал ВШЭ. 2003. № 2. С. 221-230.

24. Яковлев А.А., Симачев Ю.С., Данилов Ю.А. Корпоративное управление в российских компаниях: до и после кризиса // Препринт WP1/2010/02, Серия WP1 Институциональные проблемы российской экономики. М., 2010.

25. Яковлев А.А., Данилов Ю.А. Российская корпорация на 20-летнем горизонте: структура собственности, роль государства и корпоративное финансирование // Российский журнал менеджмента. 2007. № 5(1). С. 3-34.

26. Dolgopyatova, T., Iwasaki, I., Yakovlev, A. (2009), Organization and Development of Russian Business: A firm-level Analysis. Palgrave Macmillan. 